\title{
Lipid Profiles of American Collegiate Football Athletes in Response to Fall Preseason Camp
}

\section{DUSTIN JOUBERT, JONATHAN M. OLIVER, STEVEN E. MARTIN, JUSTIN DOBSON, STEVEN E. RIECHMAN, J.P. BRAMHALL, JOHN S. GREEN, DAVID WEIR, JON TANGUAY, and STEPHEN F. CROUSE}

\section{Texas AEM University, College Station, TX.}

Recent studies show former football athletes, especially football linemen, to be at increased cardiovascular disease risk. However, the lipid profiles of American NCAA Football Bowl Subdivision (FBS) players in response to sport participation are currently unknown. To quantify the effects of participation in fall preseason football training camp on the blood lipid profiles in NCAA FBS athletes. Seated venous blood samples were drawn in the morning after an overnight fast from 51 football players $($ age $=20 \pm 2 \mathrm{yr}$, weight $=232.8 \pm 40.8 \mathrm{lb}$, height $=73.9 \pm 2.6 \mathrm{in})$ and analyzed for total cholesterol (TC), LDL-cholesterol (LDL-C), HDL-cholesterol (HLD-C), and triglyceride (TG). Samples were obtained on two separate occasions corresponding to the beginning of fall preseason football camp, and again 16 days later near the end. Data were analyzed by paired t-test. See table, values are means $\pm \mathrm{SD},{ }^{*}=p \leq 0.001$.

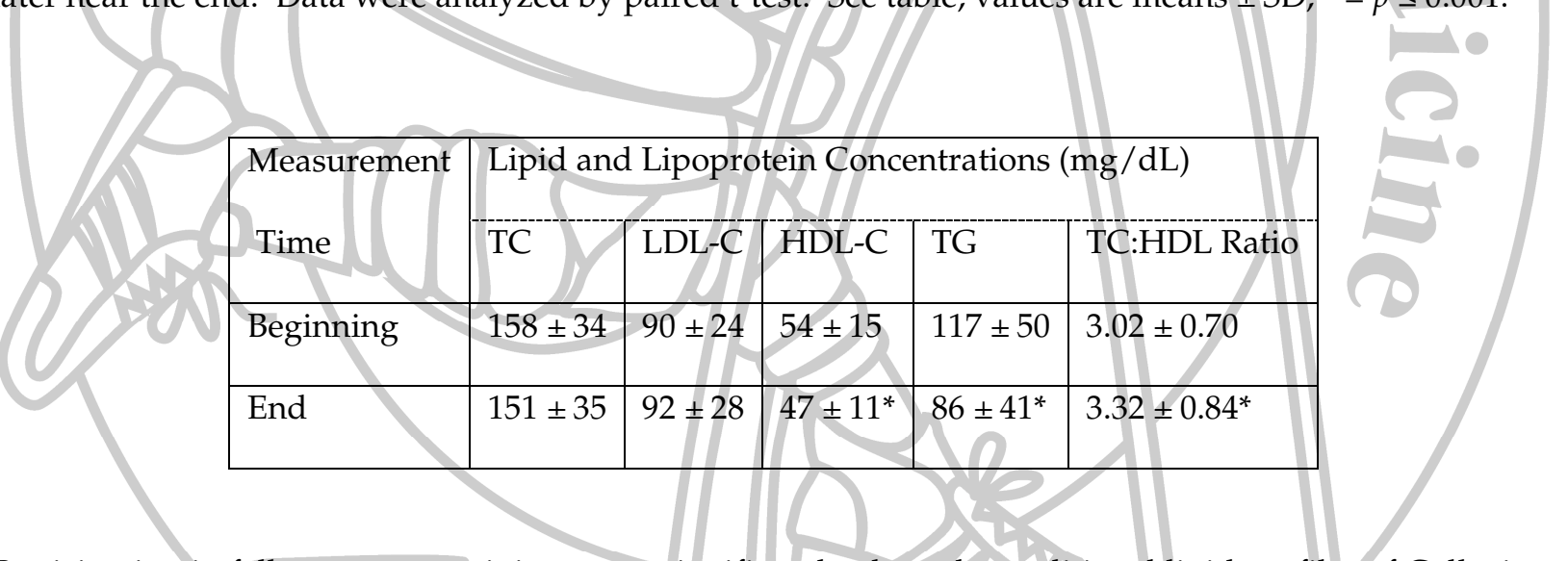

Participation in fall preseason training camp significantly alters the traditional lipid profiles of Collegiate FBS athletes. These lipid changes suggest a pro-inflammatory state with high energy utilization, and are consistent with the hypothesis that LDL-C is necessary for the structural repair of damaged tissue.

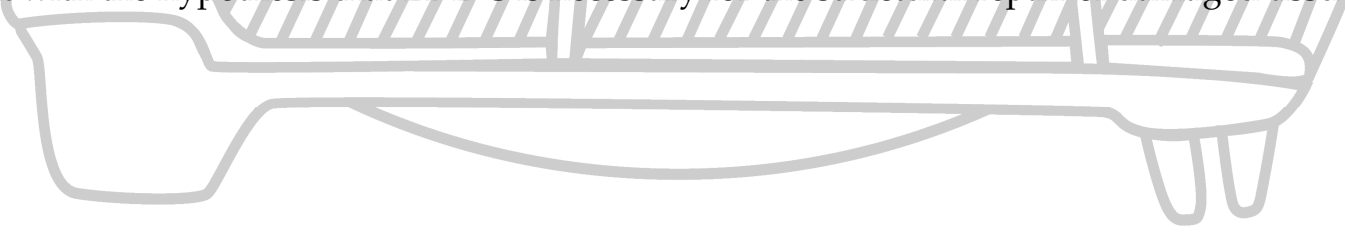

